\title{
Geometric Accuracy of Large Machine Tools
}

\author{
Michal Holub ${ }^{1, *}$, Jiri Rosenfeld ${ }^{2}$ \\ 1 Brno University of Technology, Faculty of Mechanical Engineering, Department of Production Machines, Systems and Robotics, Technicka 2896/2, \\ 61669, Brno, Czech Republic \\ 2 Slovacke strojirny, a. S., Nivnicka 1763, 68828 Uhersky Brod, Czech Republic, E-Mails: Rosenfeld.Jiri@sub.cz
}

Abstract: This article describes the issue of geometric accuracy of large machine tools. The operation and maintenance of large CNC machine tools is usually affected by a number of aspects related to large workpieces and spaces at the machine installation site. It is the size of the working space and the large dimensions of the production halls that very often have a major impact on the operation of these machines. Large workpieces remain clamped on the machine for weeks and are therefore affected by the changing environment. The presented study captures and presents changes in the ambient conditions of a large CNC machine tool, including its effects on the geometric accuracy of the machine. The first part of the article describes the geometric errors of the assessed machine. The second part also presents selected ambient conditions of the machine with the resulting measured data. The last part of the presented study summarizes the conclusions describing the influence of ambient conditions on the geometric accuracy of the machine.

Keywords: Large machine tools; large workpiece; geometric accuracy, volumetric accuracy

\section{Introduction}

Machining of large parts is one of the most demanding technological operations, especially in the area of production accuracy. Large machine tools are described in publication [1]. The manufacturers of large machines, as well as their users, strive to increase production accuracy due to the ever-increasing requirements for production tolerances [2]. Important geometric errors of large machines are the positioning error and the squareness error. These errors not only affect the production accuracy, but also the resulting accuracy of the workpiece positioning.

The positioning error or the error of position accuracy setting according to ISO 2302: 2014, which can be as large as $0.1 \mathrm{~mm}$ on large workpieces, belongs to the group of quasi-static ones. These very slow changes in the ambient conditions during the season of the year can cause changes in the geometric accuracy of the machine.

In large CNC machine tools operated in large production halls, the environmental changes are visible and essential for the behaviour of the machines in terms of geometric accuracy. The presented work describes a case study of the behaviour of a large CNC machine tool of the horizontal boring and milling machine (HCW3) type. The first part describes the geometric deviations of the HCW3 machine and individual types of geometric accuracy measurements. The second part presents a system for monitoring the machine tool, including a record from two monitored periods. The last part presents the resulting analyses of positioning accuracy and temperature settings in a given period.

\section{Geometric errors of horizontal boring and milling machines}

*Corresponding author: Michal Holub, E-mail:michal.holub@vutbr.cz 
the ISO 230 and ISO 10791 series. These standards are used mainly as the sum of the handover protocol between the machine manufacturer and the customer. Within the operation of the machine and the part of its life cycle - Use of the machine [1], internal test procedures of individual CNC machine tools are very often designed. Their use is usually realized in production machines where workpieces with high added value are machined or it is very difficult to replace these machines in the production process due to the incompetent production. The following section presents a machine tool that is constantly monitored and analysed to ensure the production competence. Tests of the effect of temperature on the volumetric error and on the change in lengths identified by the indirect method were presented in the publication [3]. It was a small CNC machine tool placed in the air-conditioned chamber.

\subsection{Demonstrator}

The study is carried out on the horizontal boring and milling machining centre HCW 3 - Skoda Machine Tool (Fig. 1.) The coordinate system of demonstrator corresponds to the kinematic chain W (Workpiece)-X-Y-Z-W-T (Tool).

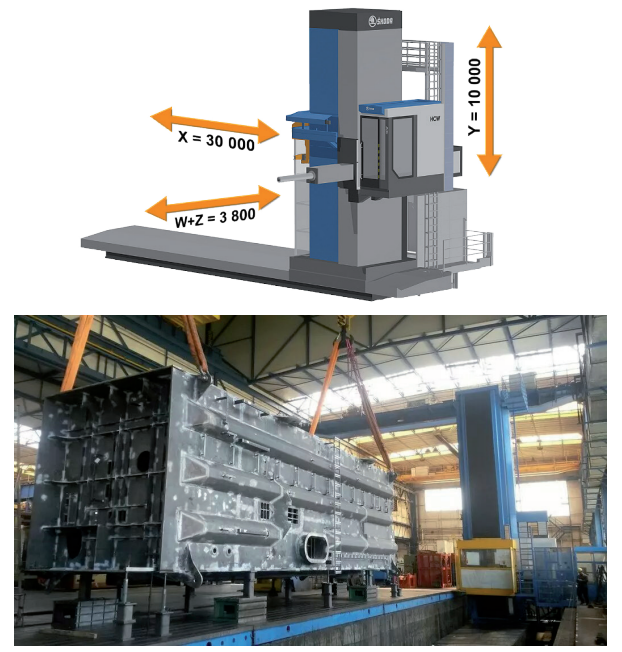

Figure 1: (a) Demonstrator HCW 3 Skoda Machine Tools [czSMT.cz]. (b) Operation of HCW 3 in the production premises of Slovacke strojirny [Slovacke strojirny].

Table 1 defines the start of the individual axes and the start and end of the measured workspace for different measurement of HCW 3 with laser interferometer (LI) and LaserTRACER (LTC).
Table 1: HCW 3 machine parameters.

\begin{tabular}{|l|l|l|l|}
\hline & $\begin{array}{l}\text { Start Axis Machine/ } \\
\text { LI/LTc } \\
{[\mathrm{mm}]}\end{array}$ & $\begin{array}{l}\text { End Axis Machine/ } \\
\text { LI/LTc } \\
{[\mathrm{mm}]}\end{array}$ & $\begin{array}{l}\text { Length Machine/ } \\
\text { LI/LTc } \\
{[\mathrm{mm}]}\end{array}$ \\
\hline $\mathrm{X}$ & $0 / 500 / 8000$ & $\begin{array}{l}26000 / 25500 / \\
16000\end{array}$ & $\begin{array}{l}26000 / 25000 \\
/ 8000\end{array}$ \\
\hline $\mathrm{Y}$ & $0 / 50 /$ & $9000 / 6050 /$ & $9000 / 6000 /$ \\
\hline $\mathrm{Z}$ & $0 /-50 /$ & $-1550 /-1550 /$ & $1550 / 1500 /$ \\
\hline $\mathrm{W}$ & $0 /-50 /--$ & $-1350 /-1350 /---$ & $1350 / 1300 /---$ \\
\hline
\end{tabular}

\subsection{Geometric errors of machine tools}

A CNC machine tool with three-axis kinematics can be described by 21 geometric deviations [4], [5]. Standard geometric accuracy control procedures include laser interferometer, ballbar, gauge, etc. [5].

For horizontal milling and boring CNC machine tools, it is possible to describe 23 geometric errors using the mathematical model FRB+elastic (ETALON). These are the standard errors described in ISO 841: 2001 and two other errors describing the deviation of TCP with respect to the travel of the spindle and headstock on the stand. Figure 2 shows a diagram of a cantilever machine including 21 geometric deviations.
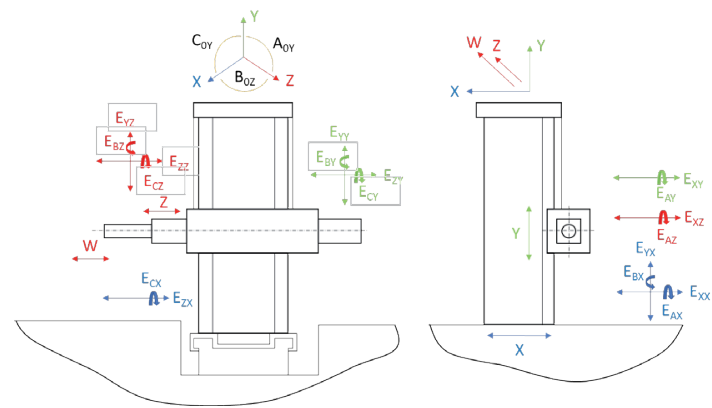

Figure 2: Geometric errors of horizontal boring and milling machines - cantilever type.

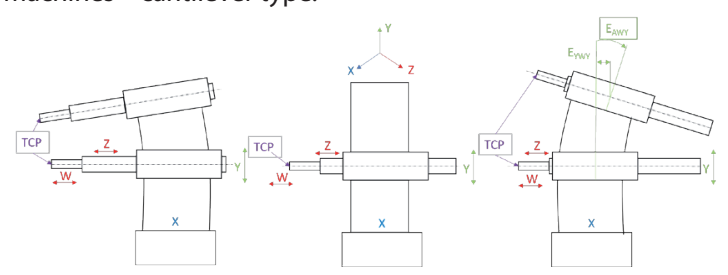

Figure 3: Geometric errors of horizontal boring and milling machines - model FRB+elastic.

Figure 3 shows the other two error parameters corresponding to the calculation model FRB+Elastic (Full rigid body) typical for horizontal boring and drilling machines. 
Thanks to such a description and a suitably designed measurement strategy, it is possible to monitor the behaviour of the machine for a long time. These results are then used in combination with the thermal behaviour of the machine and its ambient conditions to predict the behaviour of the machine or to assess the suitability of the machine deployment for a given type of workpiece.

\subsection{Design of measurement strategy}

Based on the knowledge of the geometric accuracy of the machine, its operation and the range of workpieces, it is possible to compile an appropriate measurement strategy to increase the production accuracy, as well as for long-term assessment of production accuracy with respect to its production competence.

\subsubsection{Diagnostic of machine tools with Ballbar QC20-w}

One of the basic devices for rapid diagnostics of CNC machine tools is the Ballbar device. It works on the principle of circular interpolation and is used not only for testing purposes according to ISO 230-4: 2005, but is often used for testing purposes designed for a specific kinematic structure of the machine.

As part of operations to increase the production accuracy, this device was used as a verification measuring device. Figure 4 shows an example of a circular interpolation measurement on a $220^{\circ}$ radius on the HCW3 machine (Fig. 4 a) at point P1 (Fig. 4 b). The results are archived for a long time and assessed with measured ambient conditions.
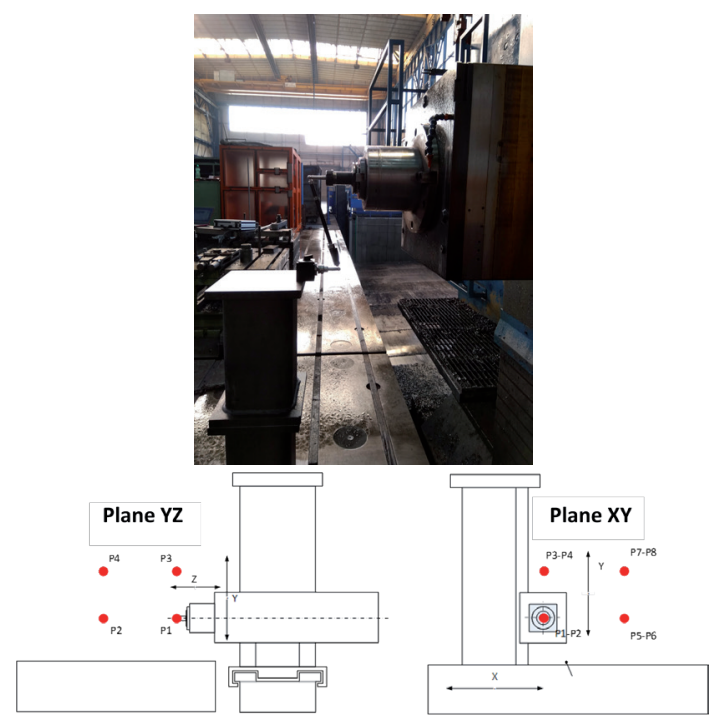

Figure 4: (a) Ballbar measurement of HCW 3. (b) Ballbar positions.

\subsubsection{Positioning error measurement with laser interferometer}

Another group of tests are measurements according to ISO 230-2: 2014. The measurement takes place in selected travels of axes according to Tab. 1. The measurement is again used not only to increase the accuracy and repeatability of positioning, but also to assess the environmental effects on the change in length. These effects are more significant here due to significant changes in ambient temperatures than is the case with medium and small CNC machine tools. Measurements according to ISO 230-2: 2014 are part of each planned inspection cycle and are shown schematically to determine the accuracy and repeatability of the X-axis positioning (Fig. 5).

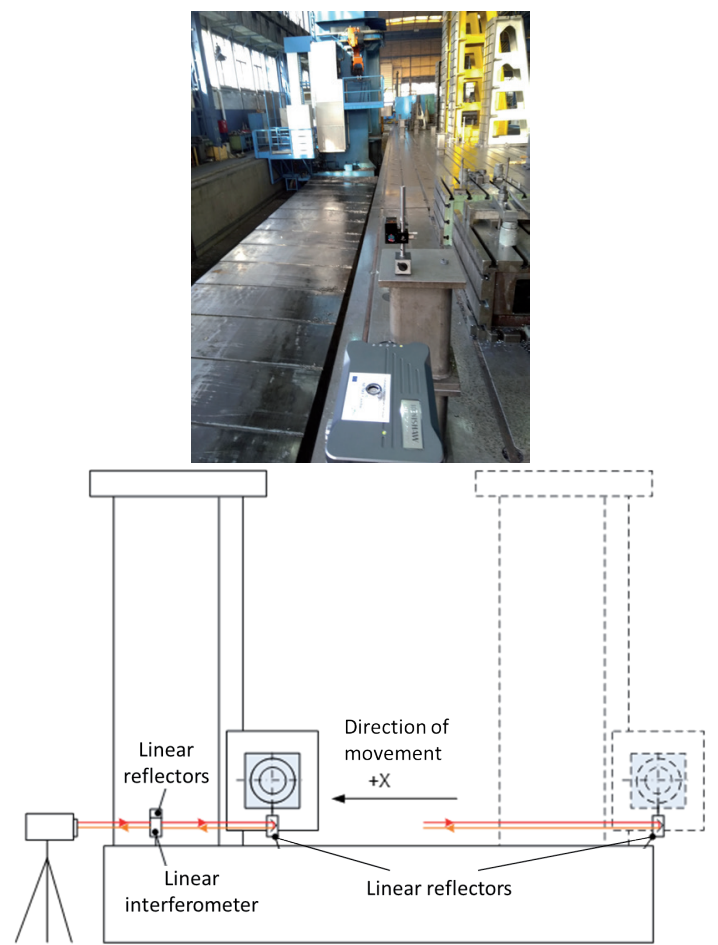

Figure 5: (a) Positioning measurement of X Axis of HCW 3. (b) Laser interferometer positions.

\subsubsection{Volumetric error measurement with LaserTRACER}

The measurement of the volumetric deviation on the machine is realized by means of the measuring device laserTRACER in the travel of the axes according to Tab. 1. The measurement is based on the principle of sequential multilateration and communication using the trigger interface. An example of the HCW3 machine measurement is shown in Fig. 6a, including the measurement 
strategy of Fig. 6b. The principle of measurement of machine tools using training interferometers by the multilateration method is described in more detail in publications [6] [7].
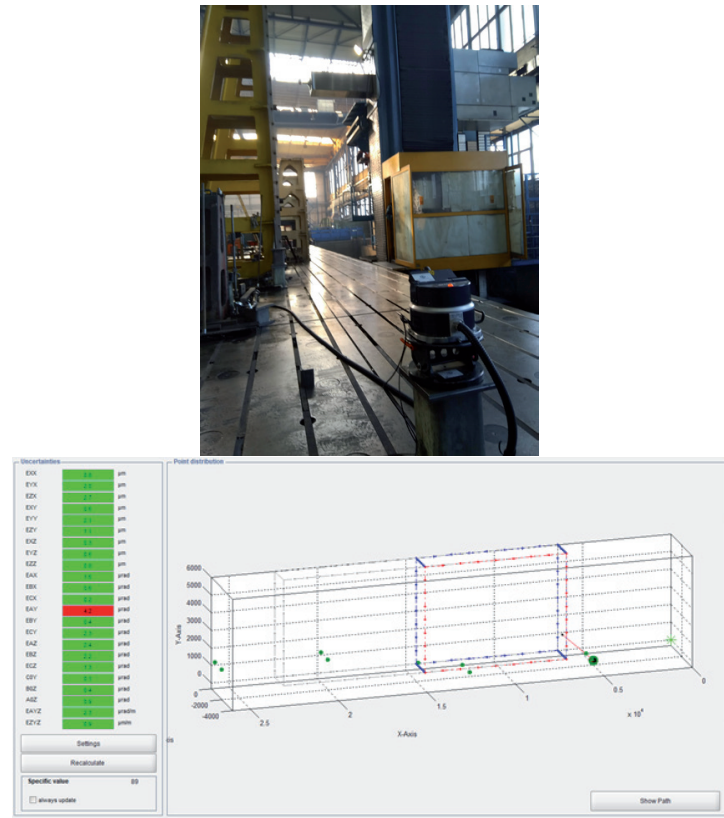

Figure 6. (a): Volumetric error measurement of HCW 3. (b): LaserTracer positions.

\section{Environmental monitoring}

To analyse the measured data of the geometric accuracy of the machine in relation to the surrounding environment, the machine was equipped with temperature sensors type of Pt1000 located on the frame of the machine and its surroundings. The following sections of this chapter present the arrangement of the individual sensors chosen according to the long-term experience of the machine operator.

\subsection{Design of Environmental monitoring}

Figure 7 schematically shows the arrangement of the sensors with an example of the online display of temperatures on the HCW3 machine for the $X$ and $Y$ axes. On the $X$ axis, there are a total of nine sensors under the machine covers and five sensors on the outside of the bed. Sensors located on the $Y$-axis are both under the $Y$-axis cover and on the outside of the stand.

\subsection{Temperature profile}

Figures 8 and 9 show the profile of the measured temperatures of one day in July (Fig. 8) and November (Fig. 9). During both days the machine

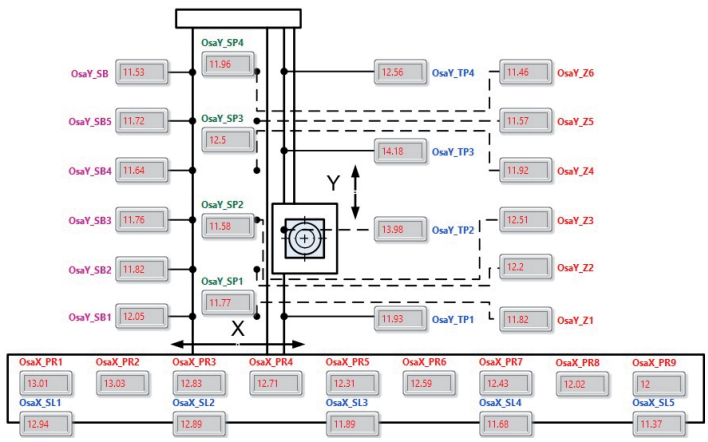

Figure 7: Actual temperature values on HCW 3.

\subsection{Geometric error of $\mathrm{HCW} 3$}

When assessing the change in positioning accuracy of individual axes, the ratio $\theta$ was monitored between the theoretically achieved value of axis elongation at the temperature gradient obtained from monitoring between individual periods and

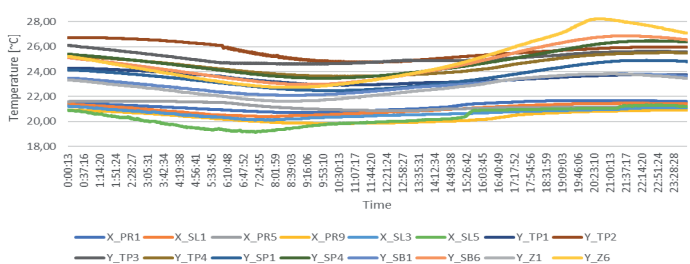

Figure 8: Temperature profile of 7th month.

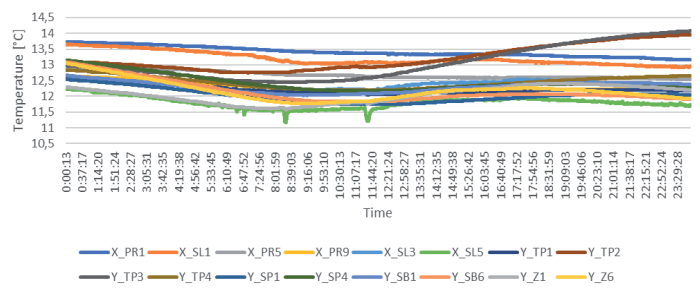

Figure 9: Temperature profile of 11th month.

was in machining mode. From the obtained courses of specific days, it can be seen how the temperature fluctuates during the day in selected places, but also the changes over 4 months. These then have a significant effect on the results of geometric accuracy.

\section{Results and Discussion}

As part of long-term monitoring of geometric accuracy in connection with ambient conditions, selected machine parameters were monitored. These were mutually assessed and evaluated. The following chapter presents the partial results. 
the actual difference of elongation according to the relation:

$\theta=\frac{E_{T}}{E_{R}}$

where $E_{T}$ is the theoretical error on the axis calculated according to the relation (2) and $E_{R}$ is the difference of errors given by the relation (3).

$$
E_{T}=L \cdot \alpha \cdot \Delta T
$$

$L$ is the assessed axis length with the temperature coefficient of expansion $a$ and the temperature change $\Delta T$.

$$
E_{R}=E_{11}-E_{7}
$$

The position setting error E11 then corresponds to the error measured in the 11th month according to Fig. 10a and the position setting error E7 corresponds to the error measured at the $7^{\text {th }}$ month according to Fig. 10b.

For the $X$ and $Y$ axes, this observed ratio is $\theta X=$ -3.016 for the $X$ axis (Fig. 10a) and $\theta Y=-2.930$ for the $Y$ axis (Fig. 10b).

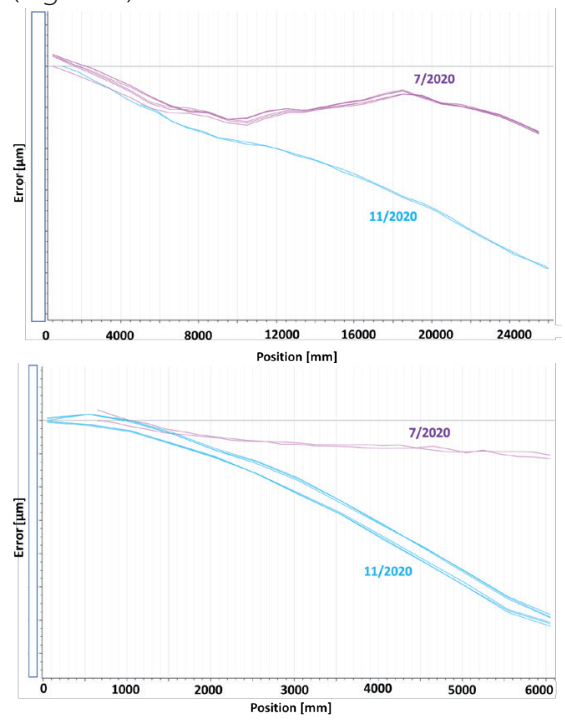

Figure 10: (a) X axis accuracy, (b) Y axis accuracy.

The results obtained for the $Z$ and $W$ axes are calculated only as indicative from the same temperature gradients as for the $X$ and $Y$ axes. It should be noted that temperatures on the $Z$ and $W$ axes, which have significantly different temperatures than $X$ and $Y$, are not monitored. Despite these circumstances, a ratio calculation was performed that is equal to $\theta_{z}=-1.598$ for the $Z$ axis (Fig. 11a) and $\theta_{W}=-1.265$ for the $W$ axis (Fig. $11 b$ ).
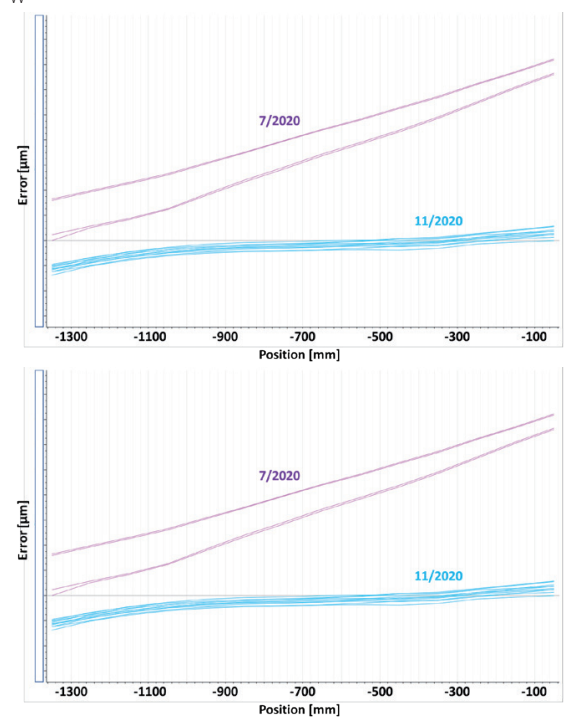

Figure 11: (a) Z axis accuracy, (b) W axis accuracy.

\subsection{Compensation of large machine tools}

Compensations in the CEC tables [8] for the Siemens sinumerik 840Dsl control system were applied as part of changes in the geometric accuracy of the machine related mainly to changes in ambient conditions. Fig. 12 shows an example of the results of the accuracy and repeatability of positioning of the $X$ and $Z$ axes before the compensation and after the activation of the compensation tables. As can be seen, with the controlled length and the ambient conditions change, the error increases linearly.
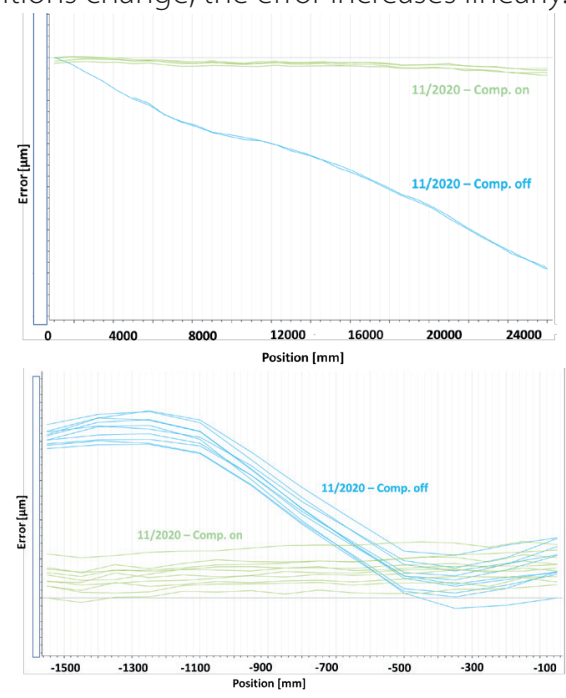

Figure 12: (a) X axis accuracy, (b) Z axis accuracy. 


\subsection{Discussion}

From the results presented above, it is evident that the change in temperature of individual groups of the machine plays an important role in its operation. As part of the long-term evaluation, there is still insufficient data to implement a system to increase the production accuracy. There are several reasons for this. The first part is still a "small" sample of data that could be used to predict behaviour. The second part is a "small" sample of suitably controlled workpieces. Both factors are gradually assessed and tested over time in cooperation with the manufacturing company. For example, monitoring of at least one annual cycle will be needed to assess the impact of the season of the year and to design an appropriate measurement cycle and individual strategies. For the X-axis, the curve oscillates in the $7^{\text {th }}$ month, where the resulting linearity corresponds to the temperature behaviour of the axis, but the obtained waveform could bring considerable inaccuracy into the results. Furthermore, it is necessary to assume a linear course of the error, such as for the $Y, Z$ and $W$ axes. This course will be monitored and evaluated as part of further research.

The question remains whether it will be possible to generalize the knowledge gained in this way, at least in terms of kinematics and machine size. For further research, it would be appropriate to obtain more temperature profiles from similar production halls and to include this knowledge in the potential generalization of the operation of large CNC machine tools.

For machine users, the results can be used to quickly correct a positioning error without the need for service. The use of such a correction depends on the version of the machine control system.

\section{Conclusions}

The submitted study presented the results of a long-term assessment of the accuracy of a large machining centre of the horizontal milling and drilling machine tool type. Based on the selected calculation model, a measurement strategy was compiled consisting of quick machine diagnostics, assessment of the accuracy and repeatability of position setting and volumetric accuracy of the machine. In conjunction with continuous environmental monitoring, a data set was created for long-term maintenance planning of the machine in order to maintain or increase its production accuracy. It is clear from the results that the stability of the geometric accuracy of the machine in changing ambient conditions can be achieved through the implementation of progressive technologies in such a demanding production process as machining of large workpieces. For example, on the $X$ and $Y$ machine axes, an agreement can be observed in the behaviour of the positioning accuracy in relation to the changing temperature. For the $Z$ and $W$ axes, it is possible to observe the same agreement, but with a significantly different ratio for comparison, due to the absence of temperature sensors directly on these machine axes.

From the point of view of today's technologies and the possibilities of monitoring selected quantities, their deployment into the machining of large workpieces can be expected in order to further increase their production accuracy.

Funding:

These results were obtained with the financial support of the Faculty of Mechanical Engineering, Brno University of Technology (Grant No. FSI-S-20-6335).

\section{Acknowledgments}

The authors would like to thank Slovacke strojirny, a.s. for access to production technologies and support. The authors would like also to acknowledge funding support from the project Application of research results with a focus on the implementation of new technologies and processes in the production of large workpieces, MPO APLIKACE III CZ.01.1.02/0.0/0.0/16_084/0008839.

\section{References}

[1] J. Marek, M. Holub, T. Marek, P. Blecha, Geometric Accuracy, Volumetric Accuracy and Compensation of CNC Machine Tools, in: Mach. Tools [Working Title], IntechOpen, 2020. https://doi.org/10.5772/intechopen.92085.

[2] R.H. Schmitt, M. Peterek, E. Morse, W. Knapp, M. Galetto, F. Härtig, G. Goch, B. Hughes, A. Forbes, W.T. Estler, Advances in Large-Scale Metrology - Review and future trends, CIRP Ann. - Manuf. Technol. 65 (2016) 643-665. https://doi. org/10.1016/j.cirp.2016.05.002.

[3] L. Groos, C. Held, F. Keller, K. Wendt, M. Franke, N. Gerwien, Mapping and compensation of geometric errors of a machine tool at different constant ambient temperatures, Precis. Eng. 63 (2020) 10-17. https://doi.org/10.1016/J. PRECISIONENG.2020.01.001.

[4] M. Holub, P. Blecha, F. Bradac, T. Marek, Z. Zak, Geometric errors compensation of CNC machine tool, MM Sci. J. 2016 (2016). https://doi.org/10.17973/MMSJ.2016_12_2016194. 
[5] H. Schwenke, W. Knapp, H. Haitjema, A. Weckenmann, R. Schmitt, F. Delbressine, Geometric error measurement and compensation of machines-An update, CIRP Ann. - Manuf. Technol. 57 (2008) 660-675. https://doi.org/10.1016/j. cirp.2008.09.008

[6] J.-M. Linares, J. Chaves-Jacob, H. Schwenke, A. Longstaff, S. Fletcher, J. Flore, E. Uhlmann, J. Wintering, Impact of measurement procedure when error mapping and compensating a small CNC machine using a multilateration laser interferometer, Precis. Eng. 38 (2014) 578-588. https:// doi.org/https://doi.org/10.1016/j.precisioneng.2014.02.008.

[7] M. Holub, Geometric Accuracy of Machine Tools, in: J. Davim (Ed.), Meas. Mach. Tribol. Mater. Forming, Mach. Tribol., Springer, Cham, 2019: pp. 89-112. https://doi. org/10.1007/978-3-030-03822-9_3.

[8] M. Holub, Kompenzace geometrické presnosti CNC obráběcích strojů, in: Konstr. CNC Obráběcích Strojů IV, MM publishing, s.r.o., 2018. 